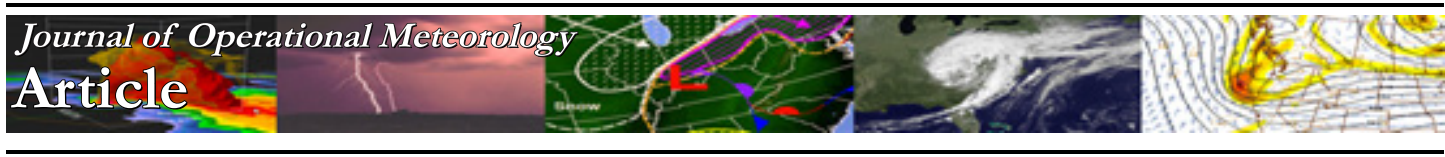

\title{
A Rare Ice Storm in the Colorado Rockies
}

\author{
MEGAN M. STACKHOUSE \\ NOAA/National Weather Service, Grand Junction, CO \\ JEFFREY D. COLTON \\ NOAA/National Weather Service, Grand Junction, CO \\ DENNIS D. PHILLIPS \\ NOAA/National Weather Service, Grand Junction, CO \\ KRISTOPHER J. SANDERS \\ NOAA/National Weather Service, Grand Junction, CO \\ MICHAEL A. CHARNICK \\ NOAA/National Weather Service, Grand Junction, CO \\ MICHAEL P. MEYERS \\ NOAA/National Weather Service, Grand Junction, CO \\ (Manuscript received 9 May 2020; review completed 3 December 2020)
}

\begin{abstract}
During the early morning hours of 9 January 2017, freezing rain developed across several valley locations in western Colorado. The resultant ice accumulation led to extremely treacherous travel conditions with hundreds of vehicle accidents reported in the vicinity of Grand Junction, Colorado and near Durango, Colorado. Additionally, widespread power outages were reported in Durango and near Steamboat Springs, Colorado. First responders were overwhelmed by the volume increase of emergency calls, and secondary services were requested from nearby municipalities to help with the increased workload. The emergency operations center in Mesa County, Colorado (Grand Junction) was activated as a result of the numerous accidents and injuries across the region. An ice storm of this magnitude has not been experienced in Grand Junction's period of record, which dates back to 1893 . A detailed investigation explores the physical processes responsible for this ice storm over the complex terrain of the Intermountain West.
\end{abstract}

\section{Introduction}

According to the National Centers for Environmental Information's Storm Data, prior to the freezing-rain event on 9 January 2017, no ice storms had ever been recorded in eastern Utah and western Colorado. Changnon and Karl (2003), using a database from 1948-2000 of average and extreme freezingrain-day values, identified a minimum of events across the Intermountain West, which comprises the Great Basin, Colorado Plateau, Middle Rocky Mountain, and Northern Rocky Mountain geographic regions. Numerous meteorological ingredients must come together to produce freezing rain, and a slight shift in any of these can drastically alter the precipitation outcome and impact. This paper will describe the meteorological environment across the region prior to and leading up to the ice storm on 9 January. It also will highlight the anomalous nature of the storm, particularly because an event of this magnitude has not been experienced in Grand Junction's period of record, which dates back to 1893. Since 2000, the National Weather Service (NWS) forecast office in Grand Junction, Colorado has issued seven Freezing Rain Advisories, and the Ice Storm Warning designation was used for the first time on 9 January 2017. Additionally, NWS local storm reports

Corresponding author address: M. M. Stackhouse, 2844 Aviators Way, Grand Junction, CO 81506. 
since 2000 indicate there were at least four additional days when freezing rain was reported, either by trained weather spotters or automated surface observations, when no advisory was in effect. However, these reports may include all freezing precipitation events, including both freezing rain and freezing drizzle, according to the American Meteorological Society's Glossary of Meteorology (Glickman 2000). Figure 1 provides a distribution of Freezing Rain Advisories separated by forecast zones issued by the Weather Forecast Office (WFO) in Grand Junction (GJT). The rarity of such an ice storm played a role in the decision-making process at WFO GJT and impacted the final forecast prior to the onset of freezing precipitation on 9 January 2017.

Although freezing-rain environments have been studied extensively in the continental United States, most referenced cases are from the Pacific Northwest or east of the Rockies. Many of the studies examining freezing precipitation across the Intermountain West, including the Front Range of Colorado, show freezing drizzle as the predominant form of freezing precipitation (Robbins and Cortinas 1996; Bernstein and Brown 1997; Bernstein 2000; Changnon and Karl 2003; Cortinas et al. 2004). Valley cold pools (Reeves and Stensrud 2009) are often associated with freezing precipitation in the Intermountain West. In these events, snow falls and melts in a warm layer aloft, and the resultant raindrops fall into a sub-freezing cold layer near the surface. Meyers et al. (2015) examined a unique freezing-rain event across northwestern Colorado at the Steamboat Resort ski area. In this event, it was suggested that snow changed to freezing rain at the resort as the upperlevel seeder cloud dissipated, resulting in a supercooled warm-rain, freezing-rain process (Rauber et al. 2000), which does not require a $>0^{\circ} \mathrm{C}\left(>32^{\circ} \mathrm{F}\right)$ warm layer. Regardless of the mechanisms involved, ice storms account for a great percentage of property damage and weather-related injuries (Kocin 1997). We will be discussing in detail an event consisting of precipitation falling through a melting layer and then into a valley cold pool.

The 1200 UTC 9 January 2017 sounding from WFO GJT exhibited a classic "warm nose" with a large area of above-freezing temperatures evident above the surface, especially when compared to the observed soundings at 0000 UTC 9 January and 0000 UTC 10 January (Fig. 2). This elevated warm layer was sufficient for completely melting the hydrometeors falling through the layer before the strong valley inversions allowed freezing precipitation to occur at the surface. However,

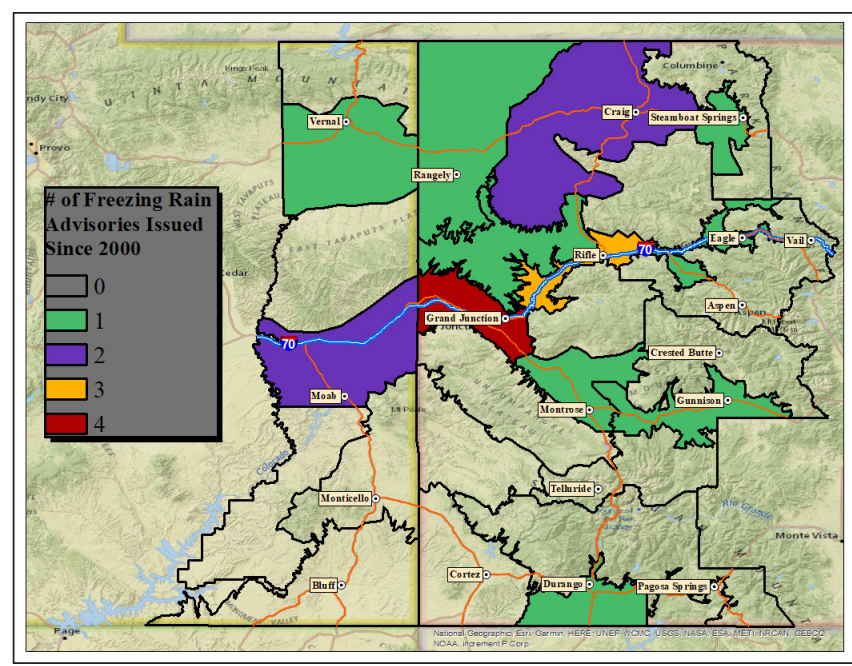

Figure 1. Distribution of Freezing Rain Advisories per forecast zone within the GJT CWA issued 2000-2019. Click image for an external version; this applies to all figures and hereafter.

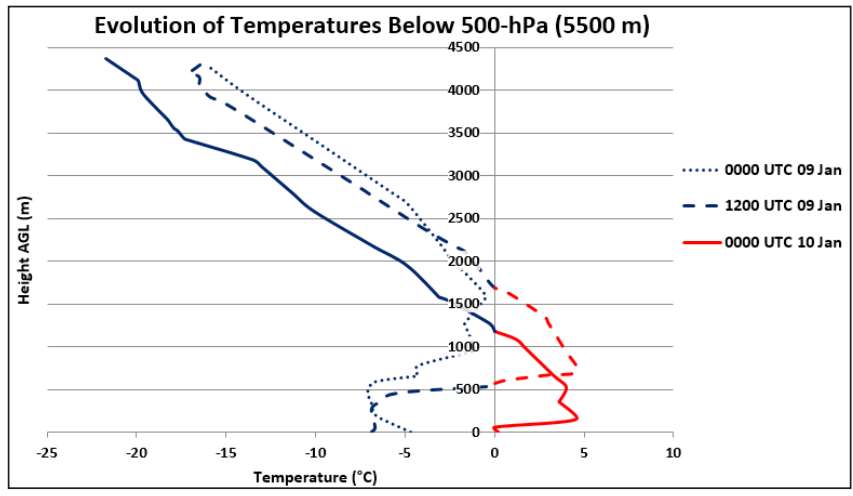

Figure 2. Evolution of temperatures $\left({ }^{\circ} \mathrm{C}\right)$ below 500 $\mathrm{hPa}$ or near $5500 \mathrm{~m}$ at KGJT (dotted line, 0000 UTC 9 January; dashed line, 1200 UTC 9 January 2017; solid line, 0000 UTC 10 January).

by the time the sounding was processed around 1400 UTC, freezing rain was ongoing already.

As previously mentioned, the low frequency of freezing-rain occurrences in the Intermountain West, particularly in western Colorado, has prevented much research being done, apart from Meyers et al. (2015). Robbins and Cortinas (2002) found that variability in the synoptic-scale and local environments associated with freezing rain suggests that forecast techniques derived for specific geographical locations should not be applied universally. The main synoptic features that lead to freezing rain across the aforementioned favored geographic regions include cold-air damming, isentropic lifting over a stationary arctic air mass 
with a surface baroclinic zone, and closed cyclones associated with strong vorticity dynamics. Although the Pacific Northwest has similar orographic forcing to the Intermountain West, the influence from nearby water sources makes a direct comparison impossible. However, in the presence of an elevated warm layer, upward motion, and sufficient moisture, the valleys within the complex terrain across the Pacific Northwest were favored areas for freezing rain because of the presence of sub-freezing air that settled there (Robbins and Cortinas 2002).

\section{Antecedent conditions}

The 2016/2017 cool season ended anomalously wet for much of the western United States. This can be attributed to seasonal and intra-seasonal circulations occurring in the upstream Pacific producing favorable conditions for frequent land-falling atmospheric rivers (ARs). One-third of the 2017 Water Year AR events through March were classified as strong to extreme by the Center for Western Weather and Water Extremes (CW3E). This classification system was refined by Ralph et al. (2019) to a numerical scale that is meant to characterize the strength and impacts of ARs. The strength of an AR is derived via an Eulerian perspective of the maximum vertically integrated water vapor transport (IVT) and the duration of AR conditions. By default, an AR is restricted to IVT $\geq 250 \mathrm{~kg} \mathrm{~m}^{-1} \mathrm{~s}^{-1}$. The impacts of an AR are characterized by descriptors ranging from "Primarily Beneficial" to "Primarily Hazardous," with duration as a fundamental factor [see Table 1 from Ralph et al. (2019)]. Not surprisingly, the ice storm of 9 January 2017 occurred in the wake of an AR event that was categorized as extreme when it impinged upon the central and northern California coast beginning on 8 January (Fig. 3 ).

Rutz et al. (2015) categorized landfalling ARs into three geographic-based regimes with mainly anticyclonic, inland-penetrating moisture trajectories found north of Cape Mendocino and cyclonic trajectories to the south of this point as seen in Fig. 4. The synoptic pattern and extreme IVT along the West Coast early in the 8 January AR event clearly reflect characteristics of Regime 2. Again, from Rutz et al. (2015), this regime makes up roughly a quarter of landfalling ARs, with approximately $4 \%$ of this number able to penetrate the interior West. Though rare, the character of this AR event increased the probability of impacts being realized over portions of eastern Utah and western Colorado on
Table 1. Impacts of an AR as defined by Ralph et al. (2019).
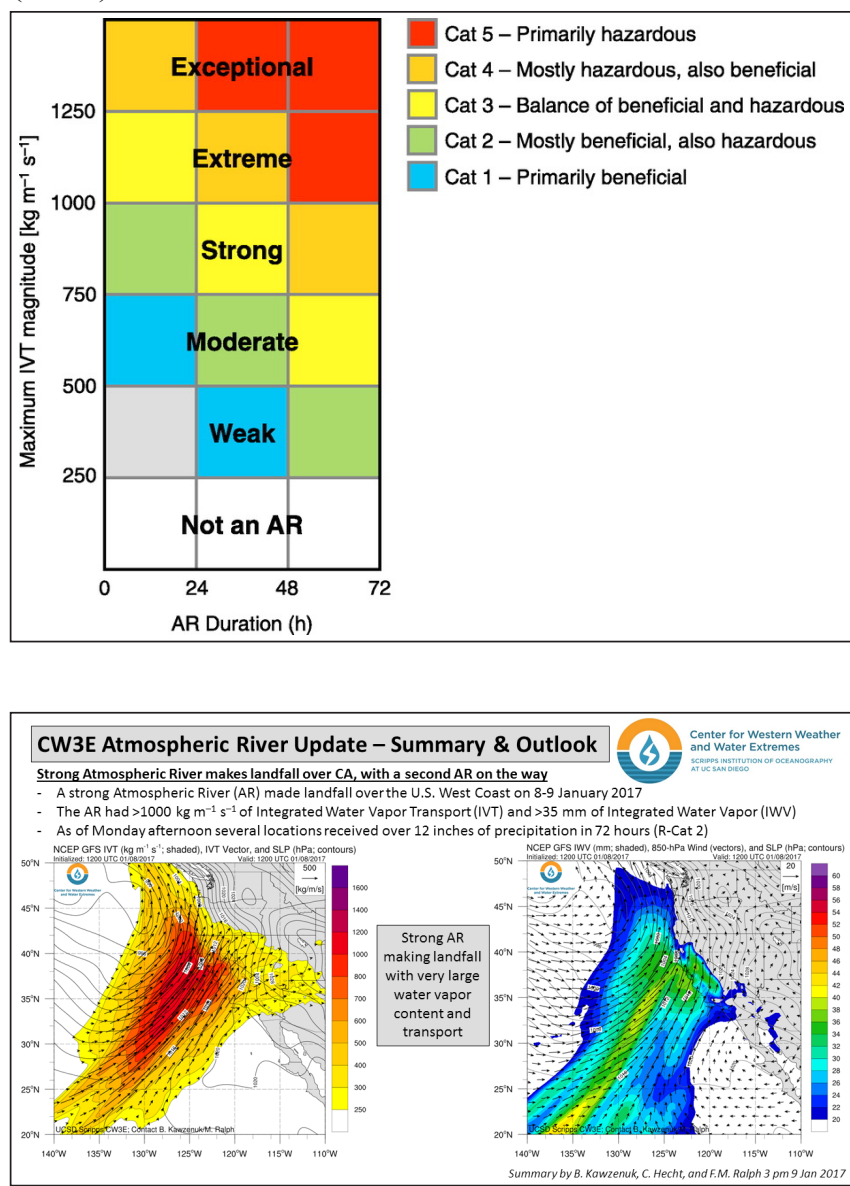

Figure 3. Extreme AR on 8 January 2017 that penetrated inland. Image courtesy of CW3E

the morning of 9 January. This anomalous moisture source was recycled throughout the weekend as several embedded shortwaves tracked across the region. These waves of energy served to enhance the persistent orographic lift across the Colorado mountain ranges with the outcome being periods of especially heavy snowfall rates. Along the Continental Divide-which includes the Park, Gore, Elk, Sawatch, and San Juan Mountain ranges - storm total snowfall measurements of 0.30 to $0.61 \mathrm{~m}$ ( 1 to $2 \mathrm{ft}$ ) were common with up to

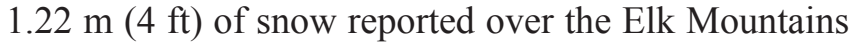
of central Colorado by the storm's end on 10 January. The complex terrain of Colorado can be viewed in further detail in Fig. 5.

Extended models had anticipated the occurrence of the AR event several days in advance with a general consensus that a surge of moisture would reach the GJT County Warning Area (CWA) by 8 January as the first in a series of disturbances moved through the 


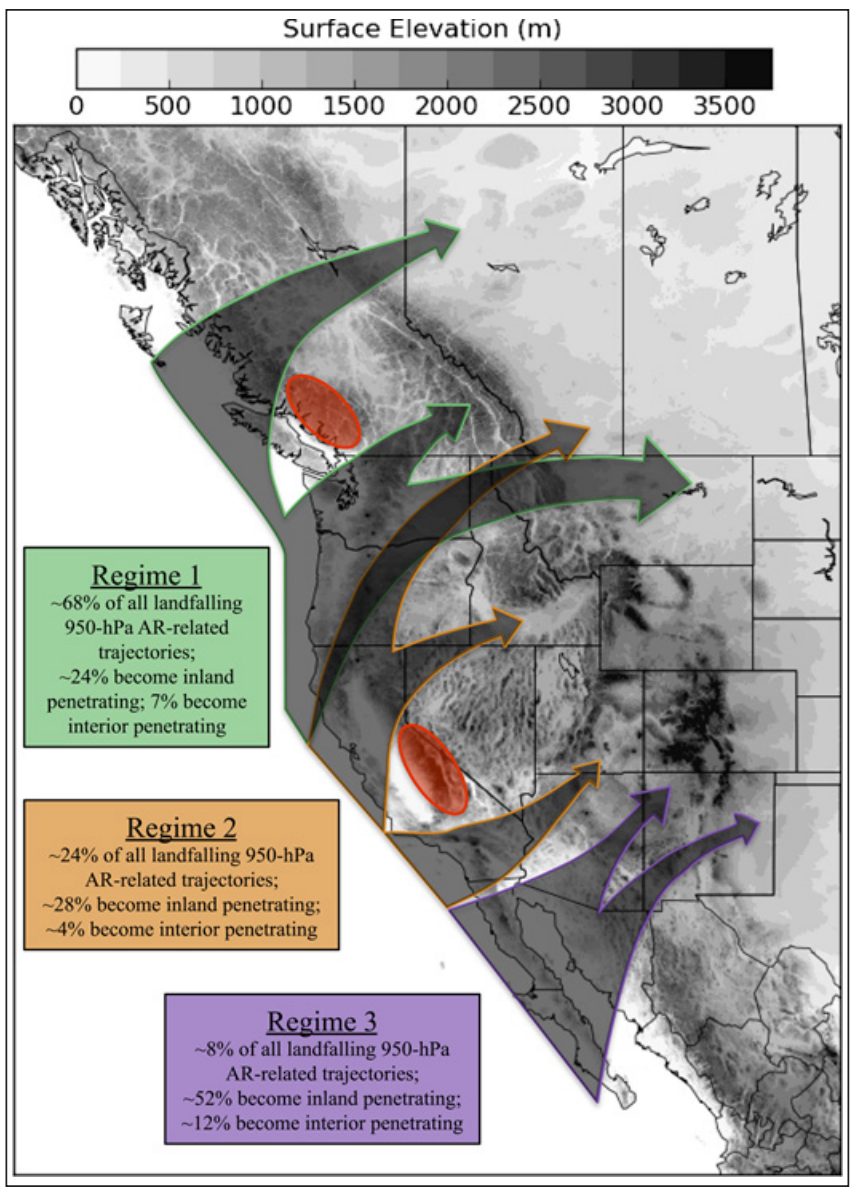

Figure 4. Schematic from Rutz et al. (2015) showing the primary pathways for the penetration of $950 \mathrm{hPa}$ AR-related trajectories into the interior of western North America. Pathways associated with regimes 1-3 are represented by green, orange, and purple arrows, respectively. Regions associated with frequent AR decay are shaded in red. Topography is shaded in grayscale. Note that, although this schematic highlights common regimes and pathways, individual trajectories follow many different paths.

area. A strong, closed, upper-level low pressure over the Gulf of Alaska, paired with a jet stream rounding the base of the trough, allowed for the continual plume of moisture into the Intermountain West. The aforementioned shortwave that was projected to move through the area on 8 January began to break down the previously situated ridge of high pressure. The second, stronger shortwave trough had an anticipated arrival time of early to midday 9 January with precipitation increasing and becoming more widespread as a result. Forecast models continued to focus on the abundance of moisture prior to and continuing through the duration of the event. To reinforce how moist the atmosphere

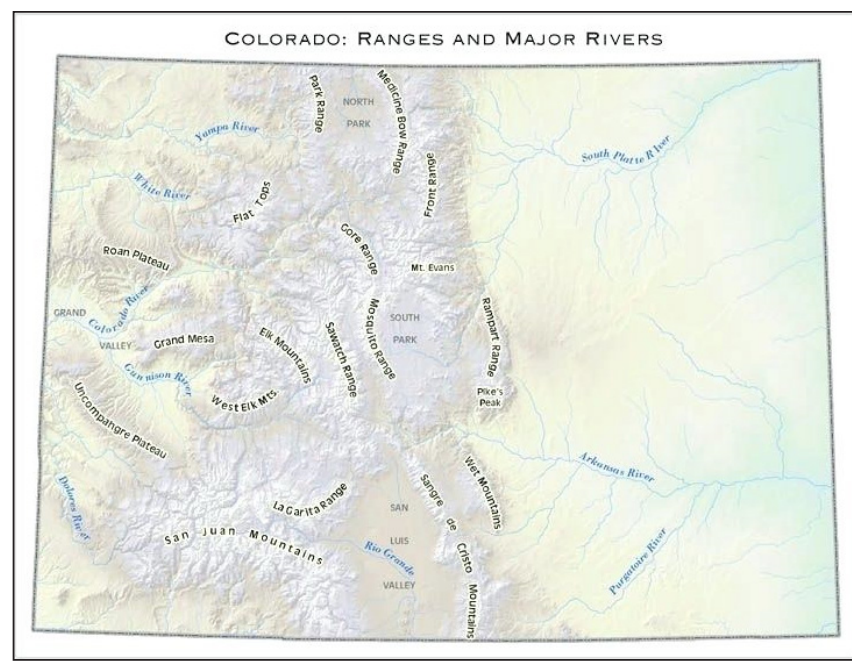

Figure 5. Mountain ranges and major rivers across the state of Colorado.

was during this time, models from the 0000 UTC 9 January run had forecast precipitable water (PWAT) values ranging from 10.2 to $15.2 \mathrm{~mm}(0.40-0.60 \mathrm{in})$. The climatological normal for early January is around $6.4 \mathrm{~mm}(0.25 \mathrm{in})$, which would put the forecast PWATs at $160-240 \%$ above normal (based on the precipitable climatology around Grand Junction, Colorado; Bunkers 2006). Additionally, the 1200 UTC sounding from WFO GJT set a new daily PWAT record of $13.7 \mathrm{~mm}$ (0.54 in), which was $208 \%$ above the climatological normal (Bunkers 2006). Forecast dewpoint depressions at $700 \mathrm{hPa}$, or near $3048 \mathrm{~m} \mathrm{MSL}$, ranged from $1-3^{\circ} \mathrm{C}$ $\left(1.8^{\left.-5.4^{\circ} \mathrm{F}\right)}\right.$ for the $0000-0600$ UTC period on 9 January before increasing to $5-10^{\circ} \mathrm{C}\left(9-18^{\circ} \mathrm{F}\right)$ for the 0600-1200 UTC period as another shortwave trough progressed into the area.

Prior to the AR event, strong surface temperature inversions were in place across many valley locations in the wake of an arctic air mass that moved through the region on 5 January. Daytime highs generally remained in the -10 to $-7.2^{\circ} \mathrm{C}\left(14-19^{\circ} \mathrm{F}\right)$ range. The temperature forecast for the valleys was a challenge for every forecast shift because there was not a great consensus between model guidance and local forecast knowledge on whether or not the inversions would mix out and warm as a result. The main reason for this lack of consensus was the influx of anomalously warm and moist midlevel temperatures that were forecast to arrive late in the weekend within this progressive weather pattern. If the inversions were to remain in place, the warm air would be able to rise above the subfreezing surface layers and introduce the potential for frozen precipitation to the valleys. Conversely, if the 
inversions were to mix out, a transition to rain would be the outcome in many valley locations. Additionally, increased cloud cover associated with the Pacific shortwave trough that impacted the region through the end of 7-8 January kept observed temperatures cool as the unsettled conditions limited the amount of solar radiation reaching the ground each afternoon. However, strong warm-air advection came in early on 8 January as the parent low pressure trekked across California. Given this pattern, it became likely that the southern valleys could potentially mix out of their inversions that afternoon (or come close to doing so), although the possibilities in the remaining valleys were less certain. The reason for this uncertainty was the shift from westerly flow aloft to a milder southwest component ahead of a strong cold front that would perhaps allow for at least the southern valleys to mix out.

\section{Mesoscale and observational analysis}

By the afternoon on 8 January, inversions had eroded in a few valley locations in northwestern Colorado such as Craig and Meeker, which had daytime highs of $1^{\circ} \mathrm{C}$ $\left(34^{\circ} \mathrm{F}\right)$ and $2.8^{\circ} \mathrm{C}\left(37^{\circ} \mathrm{F}\right)$, respectively. This was quite an impressive recovery in temperatures considering lows in these areas $36 \mathrm{~h}$ prior ranged between $-30^{\circ} \mathrm{C}\left(-22^{\circ} \mathrm{F}\right)$ to $-34.4^{\circ} \mathrm{C}\left(-30^{\circ} \mathrm{F}\right)$. The Automated Surface Observing System (ASOS) at the Meeker Coulter Field Airport reported winds out of the southwest with sustained speeds of 4.1-5.1 $\mathrm{m} \mathrm{s}^{-1}(8-10 \mathrm{kt})$ that afternoon, which enabled mixing in the inversion. Elsewhere, inversions persisted across the valleys of central and southern Colorado as well as eastern Utah. Persistent low stratus and thickening high clouds resulted in warming to the -2.8 to $-1.7^{\circ} \mathrm{C}\left(27-29^{\circ} \mathrm{F}\right)$ range by the late afternoon hours on 7 January. However, midlevel warm-air advection strengthened over the next $24 \mathrm{~h}$ as a warm front pushed north into central Wyoming. This warmair advection, combined with enhanced southwesterly flow ahead of an approaching cold front, should have increased the chance for inversions to mix out. Observations from the ASOS at the Grand Junction Regional Airport (KGJT) did not validate this claim. Winds were generally calm during the morning hours of 8 January under the inversion, with light snow and fog occurring from 1225 to 1635 UTC as temperatures ranged from -7.2 to $-6.7^{\circ} \mathrm{C}\left(19-20^{\circ} \mathrm{F}\right)$. Calm winds prevailed through the early afternoon with light snow redeveloping from 1800 to 2100 UTC. Temperatures during this time only rose to $-4.4^{\circ} \mathrm{C}\left(24^{\circ} \mathrm{F}\right)$. The mid-afternoon hours saw the winds shift to the westnorthwest with sustained speeds of $2.6 \mathrm{~m} \mathrm{~s}^{-1}(5 \mathrm{kt})$ or less. The cooler northern wind component persisted through the afternoon and reinforced the cold air at the surface before calm winds returned for the overnight period. KGJT would not reach above the $-4.4^{\circ} \mathrm{C}\left(24^{\circ} \mathrm{F}\right)$ mark the rest of the day.

A closer review of satellite data reveals why strong inversions persisted over the valleys of western Colorado and eastern Utah. Figure 6, a broad composite Geostationary Operational Environmental Satellite-15/13 (GOES-15/13) infrared (IR) satellite view over the contiguous United States (CONUS) at 0418 UTC 9 January, shows the general setup: a welldefined plume of moisture from the Pacific with a warmair advection regime in southwesterly flow to the right side of this feature over western Colorado. A gap in the warm-sector cloud cover is apparent over portions of east-central Utah and west-central Colorado. In Fig. 7, we see two GOES-15 IR satellite views over Utah and Colorado. The top frame at 0415 UTC shows a large area of clearing (blue) spilling in from the west into east-central Utah and west-central Colorado. Note the surface temperature in Grand Junction at this time: $-5^{\circ} \mathrm{C}$ $\left(23^{\circ} \mathrm{F}\right)$. By 0540 UTC (second frame), clouds moved back in from the west. However, in that almost $1 \frac{1}{2}-\mathrm{h}$ timeframe, the temperature dropped to $-8^{\circ} \mathrm{C}\left(17.6^{\circ} \mathrm{F}\right)$ at KGJT. Temperature drops were noted also at several other valley surface stations. In addition to the clearing skies, a snowpack that ranged from 50 to $305 \mathrm{~mm}$ (2 to 12 in) most likely enhanced radiational cooling in the valleys. Figure 8 displays surface temperatures over the course of the event. The clearing and thinning of the cloud cover are highlighted in blue; temperature drops at Grand Junction, Durango, and Gunnison, Colorado are all evident at this time. Another reason why the valley inversions did not mix out also could be related to

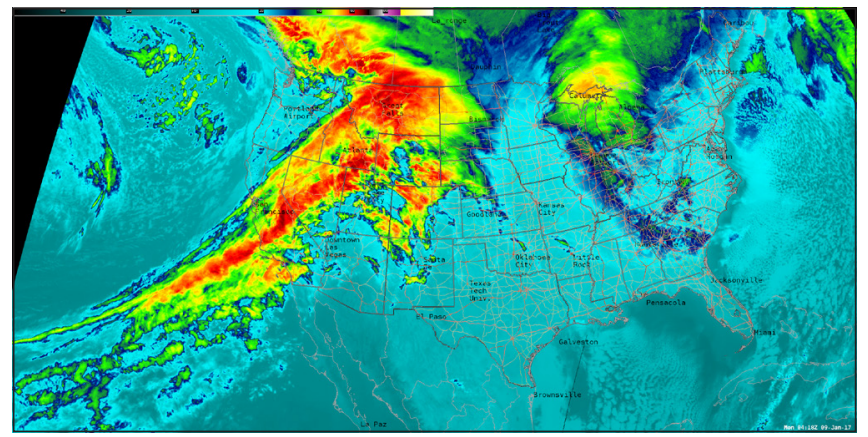

Figure 6. GOES-15/13 composite IR satellite imagery at 0418 UTC 9 January 2017: wide view depicting the broad subtropical plume affecting the western CONUS. 


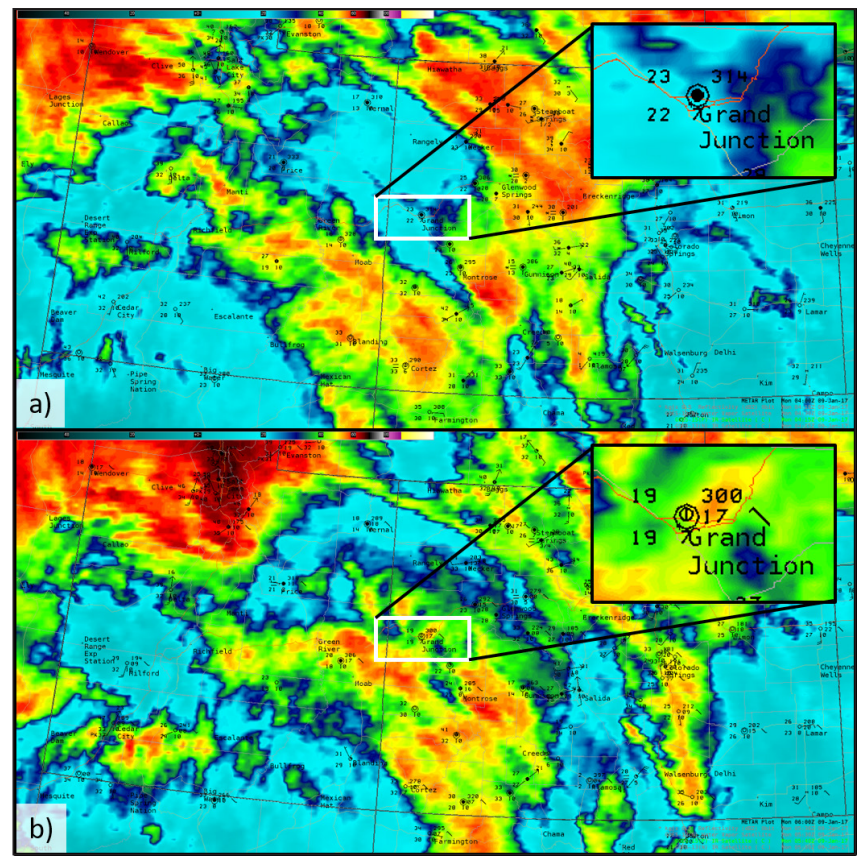

Figure 7. GOES-15 IR satellite imagery with surface observation comparison: a) 0415 UTC, b) 0540 UTC on 9 January 2017 (white rectangle, area of interest).

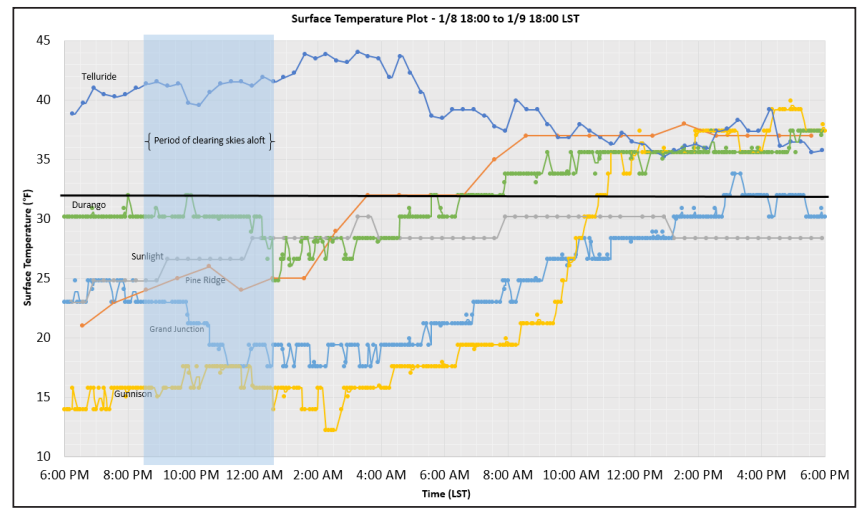

Figure 8. Surface temperature trends at various Colorado locations from 1800 (Local Standard Time (LST)) on 8 January 2017 to 1800 MST on 9 January (blue shading, period of clearing skies): light blue, Grand Junction; orange, Pine Ridge; gray, Sunlight; yellow, Gunnison; dark blue, Telluride; green, Durango.

the low-level vertical wind profile and its effect on the mountain-induced waves. Garvert et al. (2007) showed that veering winds in the lower levels dampen the effects of the downsloping associated with the mountain wave as opposed to a unidirectional wind profile that promotes stronger downsloping. The 1200 UTC GJT sounding (Fig. 9) shows veering winds from southsoutheast to southwest in the lowest $2 \mathrm{~km}$, which may have played a role in downsloping off the Uncompahgre
Plateau. Figure 10 shows the Uncompahgre Plateau's relation to the Grand Valley in greater detail, as well as other prevalent geographic features.

The effect of the strong thermal belt aloft was greatly felt the morning of 9 January. In the early morning hours, Grand Junction (elevation $1481 \mathrm{~m}$ or 4859 $\mathrm{ft})$ had a surface temperature of $-7.8^{\circ} \mathrm{C}\left(18^{\circ} \mathrm{F}\right)$ just before 1000 UTC and Telluride, Colorado (elevation $2765 \mathrm{~m}$ or $9072 \mathrm{ft})$ was reporting $6.1^{\circ} \mathrm{C}\left(43^{\circ} \mathrm{F}\right)$. Shortrange forecast models were all in agreement that the low-level inversions would dissipate during the morning. Forecaster confidence that this would happen remained low because of previous experience with valley inversions as well as the thicker snowpack that remained intact in many locations, especially over the west and east ends of the Grand Valley where Grand Junction is located. Conditions quickly changed within a few hours across southwestern Colorado with the Durango-La Plata County Airport (KDRO) warming to $0.6^{\circ} \mathrm{C}\left(33^{\circ} \mathrm{F}\right)$ just before $1500 \mathrm{UTC}$ as surface winds took on an overall southerly component. Meanwhile, in the Grand Valley, surface temperatures remained in the -4.0 to $-2.8^{\circ} \mathrm{C}\left(24-27^{\circ} \mathrm{F}\right)$ range through the morning, and as of 1600 UTC the inversion held strong. Calm winds were reported at the KGJT ASOS from 1200 to 1245 UTC before the shift from east-southeast to southwest occurred between 1255 and 1325 UTC. After that, surface winds returned to the southsoutheast and southeast directions through 1600 UTC

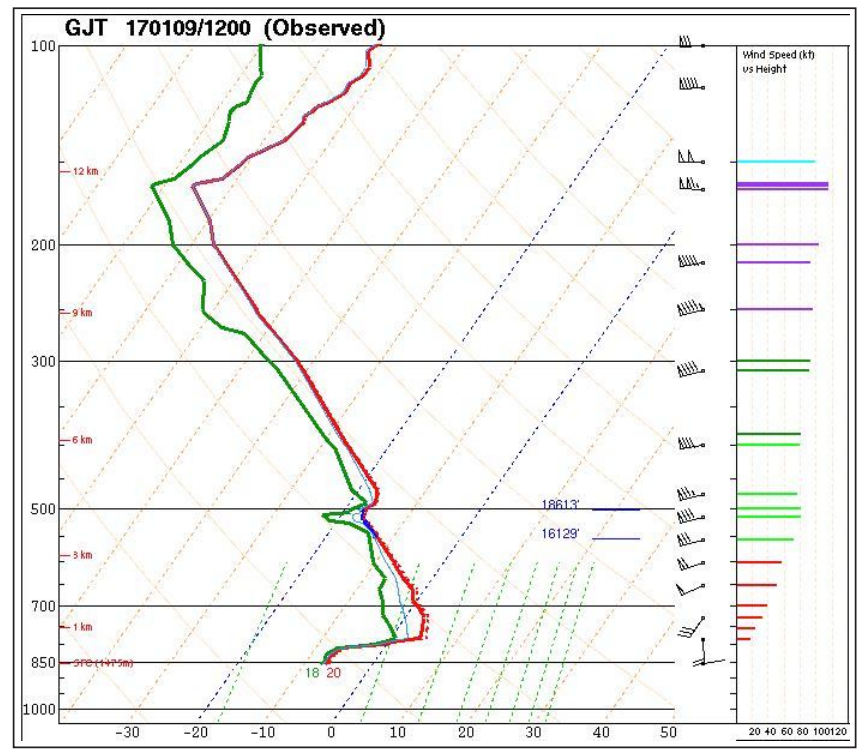

Figure 9. WFO GJT upper air sounding valid 1200 UTC 9 January 2017: temperature (red, ${ }^{\circ} \mathrm{C}$ ), environmental wet bulb temperature (dark cyan, ${ }^{\circ} \mathrm{C}$ ), dewpoint (green, ${ }^{\circ} \mathrm{C}$ ). 


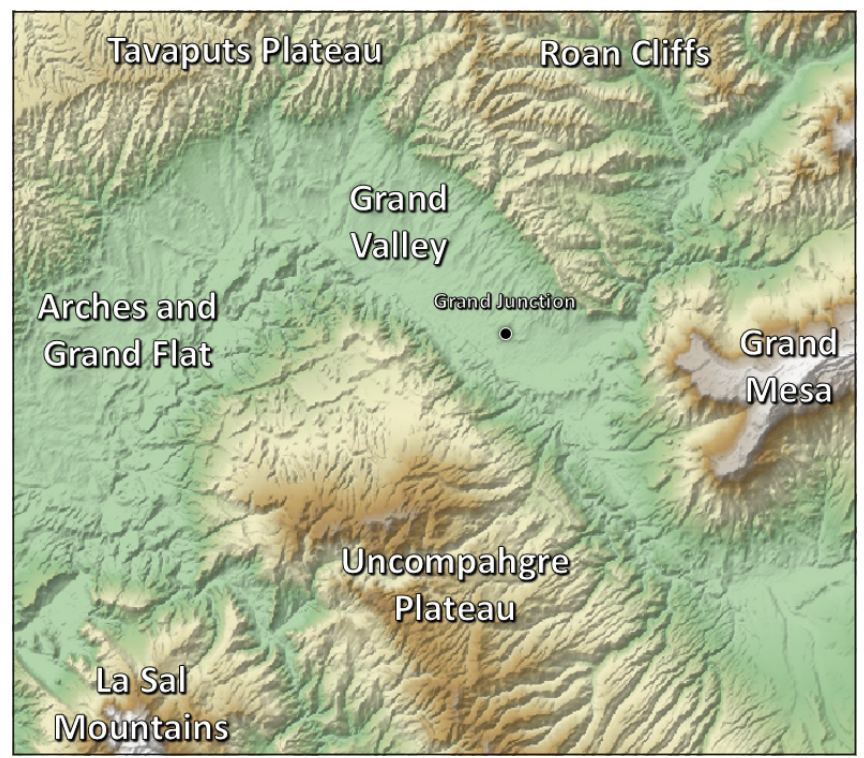

Figure 10. Topographic view of prevalent geographic features in west-central Colorado and east-central Utah, centered around Grand Junction.

with sustained speeds of $2.6-5.1 \mathrm{~m} \mathrm{~s}^{-1}(5-10 \mathrm{kt})$. By that time, around $6.4 \mathrm{~mm}$ (0.25 in) of ice had already accrued on numerous surfaces, as measured by WFO GJT NWS employees. In addition to observations by NWS employees, reports of freezing rain while it was ongoing and after the fact came through various reports (e.g., partner, public, social media, and phone calls). The only other observations of freezing rain came from the ASOS at KGJT and KDRO. The weather sensor at KGJT ASOS first reported freezing rain at 1315 UTC with the last report at 2039 UTC. Light freezing rain was the predominant intensity, though moderate freezing rain was observed between 1808 and 1845 UTC. At KDRO, freezing rain was first reported at 1125 UTC and continued through 1455 UTC before precipitation transitioned to rain. There were no known observations or reports of ice pellets during this entire event.

By the afternoon of 9 January, short-term forecast guidance continued to struggle with the evolution of this system in the lower elevations by inaccurately eroding the inversions too quickly. Even so, just before 2300 UTC, most valleys eventually climbed above freezing (though Grand Junction rose only to $0^{\circ} \mathrm{C}$ $\left(32^{\circ} \mathrm{F}\right)$ by $\left.2200 \mathrm{UTC}\right)$ as the elevated warm layer mixed down to the surface, which translated to a southwesterly component at the KGJT ASOS. The arrival of the cold front during the afternoon and evening hours saw the return of colder air aloft, which finally ended all threats of freezing precipitation, including a shift to northwest winds at KGJT. One of the warmer spots of the area was Craig, and it cooled to $-1.1^{\circ} \mathrm{C}\left(30^{\circ} \mathrm{F}\right)$ behind the front. Climatologically this was still above normal for the Craig area, which typically sees high temperatures near $-1.7^{\circ} \mathrm{C}\left(29^{\circ} \mathrm{F}\right)$ and low temperatures of $-17.2^{\circ} \mathrm{C}$ $\left(1^{\circ} \mathrm{F}\right)$ in early January.

\section{Model performance and forecast challenges}

Freezing-rain environments, and in particular the vertical profile of freezing-rain events, have been analyzed extensively. Bernstein (2000) used $48 \mathrm{yr}$ of radiosonde data from six sites to identify important regional and local influences on freezing precipitation in the United States. He determined that the thermodynamic profile during freezing rain usually had an elevated warm layer with a depth of up to $2800 \mathrm{~m}(9186 \mathrm{ft})$ and a maximum temperature within the layer that ranged from 1 to $10^{\circ} \mathrm{C}\left(34-50^{\circ} \mathrm{F}\right)$. Below the warm layer was a sub-freezing layer, which had a depth of up to $1400 \mathrm{~m}$ (4593 ft) and a minimum temperature within the layer that ranged from -1 to $-7^{\circ} \mathrm{C}\left(30-19^{\circ} \mathrm{F}\right)$. Similarly, Robbins and Cortinas (2002) found that the elevated warm layer had a median maximum temperature of $3.2^{\circ} \mathrm{C}\left(37.8^{\circ} \mathrm{F}\right)$ at a height of $1100 \mathrm{~m}(3609 \mathrm{ft})$ and a depth of $1300 \mathrm{~m}$ (4265 ft). Rauber et al. (2001) also observed that the depth of this warm layer was wellcorrelated with the maximum temperature in the layer. Stewart and King (1987) studied the melting behavior of snowflakes as they fell through the atmosphere using a numerical model based on the empirical melting rates of snowflakes as described by Stewart et al. (1984). For maximum warm-layer temperatures $>3.8^{\circ} \mathrm{C}\left(>38.8^{\circ} \mathrm{F}\right)$, all snowflakes having a mass as large as a $4 \mathrm{~mm}(0.16$ in) diameter raindrop completely melted. The 1200 UTC 9 January sounding from WFO GJT (Fig. 9) was launched approximately $2 \mathrm{~h}$ before freezing rain began. The sounding showed an elevated-warm layer that was $1000 \mathrm{~m}(3281 \mathrm{ft})$ deep with a maximum temperature of $4.6^{\circ} \mathrm{C}\left(40.3^{\circ} \mathrm{F}\right)$ and wet-bulb temperatures of $3^{\circ} \mathrm{C}\left(37.4^{\circ} \mathrm{F}\right)$ centered at approximately $800 \mathrm{~m}$ AGL (2280 $\mathrm{m}$ MSL). These values are well within range of previous research, so it was likely that the elevated warm layer was sufficient for completely melting the hydrometeors falling through even after saturation occurred. The sounding also revealed near-saturation at temperatures colder than $-10^{\circ} \mathrm{C}\left(14^{\circ} \mathrm{F}\right)$, implying that this environment was conducive to producing ice crystals above the melting layer. 
Stewart and Crawford (1995) determined that ice nucleation could lead to completely melted droplets refreezing in the cold layer in the presence of sufficiently cold temperatures $\left(<-5^{\circ} \mathrm{C}\right.$ or $\left.23^{\circ} \mathrm{F}\right)$. Zerr (1997) found by investigating soundings during ice-pellet events that temperatures in the cold layer were $<-5^{\circ} \mathrm{C}\left(23^{\circ} \mathrm{F}\right)$ and depths were $>700 \mathrm{~m}(2297 \mathrm{ft})$. The previously mentioned sounding showed a sub-freezing surface layer that was particularly cold and shallow with a minimum temperature of $-6^{\circ} \mathrm{C}\left(21^{\circ} \mathrm{F}\right)$ and a depth of $500 \mathrm{~m}(1640 \mathrm{ft})$. Despite these temperatures, ice pellets did not form during this event (not observed at Grand Junction) perhaps because of the relatively shallow depth, limiting the residence time of hydrometeors falling through that layer. Also, during the $2 \mathrm{~h}$ after the sounding launch, this cold layer could have been subjected to warming.

Forecast guidance on the evening of 8 January indicated a warm and moist layer aloft would advect across eastern Utah and western Colorado during the early morning period of 9 January. However, the strength of this warm nose was grossly underestimated in the 0000 UTC guidance with little improvement in the following model runs. This underestimation of the strength of the warm nose played a crucial role in the expected precipitation type at the onset of the event. Figure 11 helps illustrate this point by comparing the forecast maximum temperature in the 12-km North American Model (NAM) 0000 UTC sounding profile with the observed maximum temperature in the 0000 and 1200 UTC KGJT soundings. At Grand Junction itself, guidance was projecting only a $1.4^{\circ} \mathrm{C}\left(2.5^{\circ} \mathrm{F}\right)$ increase between 0000 and 1200 UTC; however, what actually occurred was a $5.1^{\circ} \mathrm{C}\left(9.2^{\circ} \mathrm{F}\right)$ increase. Similar conditions most likely occurred at KDRO because freezing rain was reported, although actual verification is impossible as the only upper air site for the western slope of Colorado is located in Grand Junction. The 0000 UTC NAM guidance for the Yampa Valley Regional Airport in Hayden, Colorado (KHDN) did indicate warming in the profile between 0000 and 1200 UTC before cooling $1.1^{\circ} \mathrm{C}\left(2^{\circ} \mathrm{F}\right)$ between 1200 and 1800 UTC. This is most likely owing to its proximity to the approaching cold front. Referring back to the findings by Stewart et al. (1984), the 0000 UTC NAM guidance for KDRO did introduce the potential for complete hydrometeor melting aloft, as the projected 1200 UTC maximum temperature of $3.9^{\circ} \mathrm{C}\left(39^{\circ} \mathrm{F}\right)$ was just above the $3.8^{\circ} \mathrm{C}\left(38.8^{\circ} \mathrm{F}\right)$ value highlighted by Stewart and King (1987). This was not the case at KGJT or KHDN,

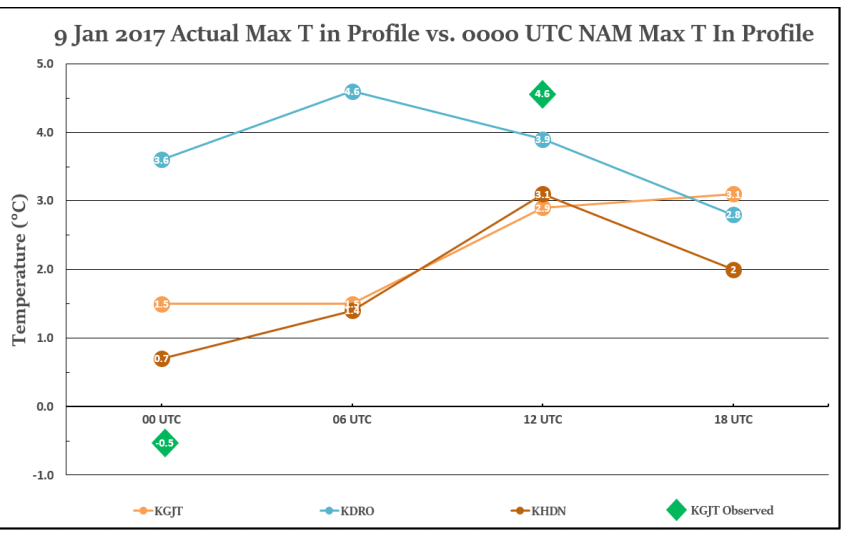

Figure 11. 12-km NAM forecast from the 0000 UTC 9 January 2017 run cycle of maximum temperature $\left({ }^{\circ} \mathrm{C}\right)$ in the profile sounding at KGJT (orange), KDRO (blue), and KHDN (brown) versus the observed maximum temperatures in the profile from the KGJT upper air soundings at 0000 UTC and 1200 UTC (green diamond).

as the maximum temperature in the profile was forecast to be $2.9^{\circ} \mathrm{C}\left(37.2^{\circ} \mathrm{F}\right)$ and $3.1^{\circ} \mathrm{C}\left(37.6^{\circ} \mathrm{F}\right)$, respectively.

An analysis of the forecast versus observed surface temperatures also revealed that model guidance was underestimating how cold the surface would be when precipitation began, again undermining forecaster confidence at WFO GJT during the period when icing occurred. Leading up to this event, forecasters were continually adjusting the model guidance by decreasing temperatures $2.7-5.6^{\circ} \mathrm{C}\left(5-10^{\circ} \mathrm{F}\right)$ cooler than guidance. The poor guidance was most notable at KGJT, where the average surface temperature from numerous forecast models [i.e., 12-km NAM, 4-km NAM, Global Forecast System (GFS), NAM Model Output Statistics (MOS), GFS MOS, and Rapid Refresh (RAP)] from the 0000 UTC 9 January run was significantly warmer than what was observed (Fig. 12). As evident in the figure, Grand Junction was projected to have a surface temperature of $1.1^{\circ} \mathrm{C}\left(34^{\circ} \mathrm{F}\right)$ at $1200 \mathrm{UTC}$ when what actually occurred was $-6.7^{\circ} \mathrm{C}\left(20^{\circ} \mathrm{F}\right)$. As a result, the hydrometeors froze on contact within the sub-freezing conditions in the strong surface inversion. The model average continued to lag through the remainder of the day with a $6^{\circ} \mathrm{C}$ $\left(10.8^{\circ} \mathrm{F}\right)$ discrepancy between what was forecasted and observed at 1800 UTC. The poor model average was the result of the wide spread between the individual forecast models, as seen in Fig. 13, which shows the hourly surface temperature forecasts initialized 1800 UTC 8 January and 0000 UTC 9 January for KGJT. The temperature forecasts valid on 1200 UTC 9 January 


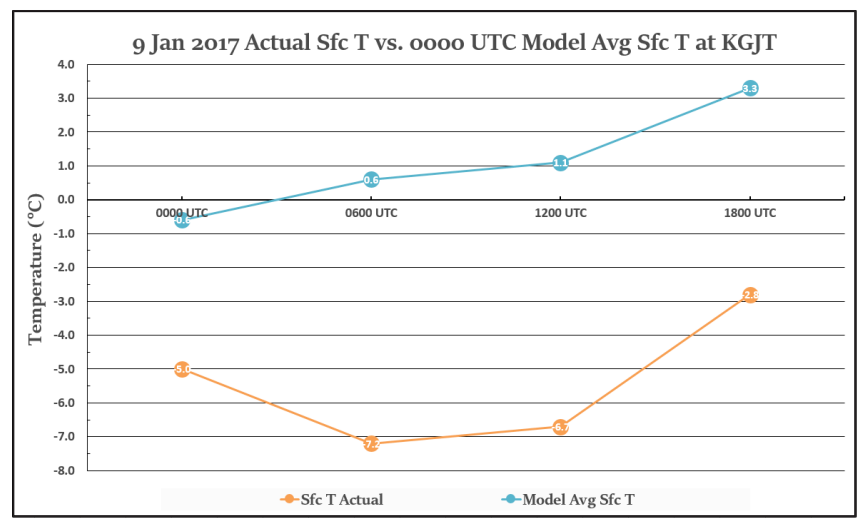

Figure 12. Model average forecast from the 0000 UTC 9 January 2017 run cycle of surface temperature (blue, ${ }^{\circ} \mathrm{C}$ ) versus actual surface temperature (orange, ${ }^{\circ} \mathrm{C}$ ) at KGJT from 0000 to 1800 UTC.

ranged from -2.8 to $6.1^{\circ} \mathrm{C}\left(27-43^{\circ} \mathrm{F}\right)$ or a $3.9-13^{\circ} \mathrm{C}$ $\left(7-23.4^{\circ} \mathrm{F}\right)$ difference from what actually occurred. At KDRO, the model average surface temperature did not vary significantly from what was observed (Fig. 14). The average and observed temperature both remained below freezing through 1200 UTC, allowing hydrometeors to freeze on contact. The 4-km NAM, which has been observed to handle complex terrain better than most other guidance, did anticipate surface temperatures would warm to $1.1^{\circ} \mathrm{C}\left(34^{\circ} \mathrm{F}\right)$ at $1200 \mathrm{UTC}$, which may have contributed to forecaster uncertainty. Finally, a detailed comparison of model average temperatures versus observed surface temperatures for KHDN (Fig. 15) indicated that between 0000 and 0600 UTC, KHDN remained trapped underneath a strong inversion with observed surface temperatures of -2.0 to $-1.0^{\circ} \mathrm{C}\left(28-30^{\circ} \mathrm{F}\right)$ compared to the above-freezing model projection. Additionally, the forecast models vastly underestimated how drastic the warming trend would be on the morning of 9 January at that location. Between 0600 and $1200 \mathrm{UTC}$, a minor climb to $1.7^{\circ} \mathrm{C}$ $\left(35^{\circ} \mathrm{F}\right)$ was anticipated; in reality, KHDN warmed to $7.0^{\circ} \mathrm{C}\left(45^{\circ} \mathrm{F}\right)$ by 1200 UTC. Surface temperatures steadily cooled between 1200 and 1800 UTC, though values remained above-freezing.

Forecast model soundings for KGJT revealed differences in the vertical temperature and moisture profiles from reality that resulted in significant errors in the evolution of precipitation type (Fig. 16). The 12-km NAM more accurately predicted the shallow sub-freezing layer and elevated warm layer compared to the GFS, perhaps because of higher resolution and ability to better resolve topography. The 0000 UTC 9 January forecast cycle of the NAM showed a sub-

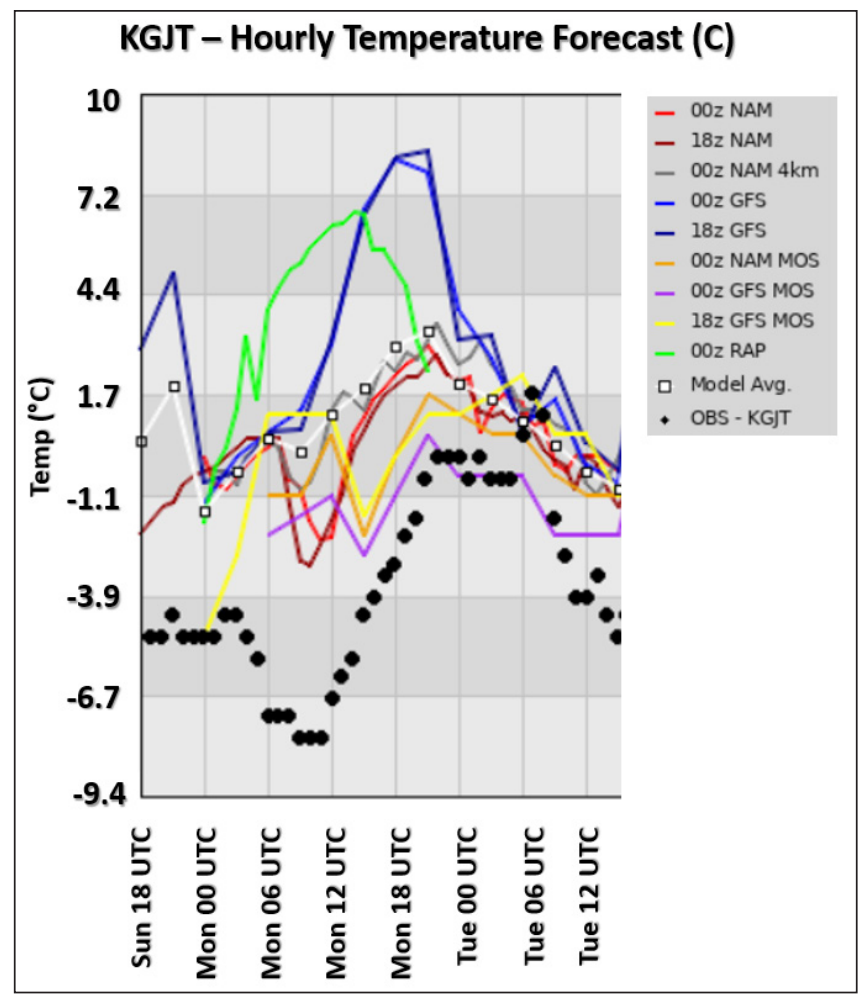

Figure 13. Meteogram of hourly surface temperature $\left({ }^{\circ} \mathrm{C}\right)$ forecasts for KGJT 1800 UTC 8 January 2017 run cycle [NAM (dark red), GFS (dark blue), and GFS MOS (yellow)] and for 0000 UTC 9 January 2017 run cycle [NAM (red), 4-km NAM (gray), GFS (blue), NAM MOS (orange), GFS MOS (purple), and RAP (green)]. Additional lines include a model average (white square, ${ }^{\circ} \mathrm{C}$ ) and observed temperatures (black diamond, ${ }^{\circ} \mathrm{C}$ ).

freezing surface layer that was $<200 \mathrm{~m}(656 \mathrm{ft})$ deep with a minimum temperature of $-2^{\circ} \mathrm{C}\left(28.4^{\circ} \mathrm{F}\right)$ valid at 1200 UTC. By 1400 UTC, the NAM warmed that layer above freezing, which was not observed until after 1800 UTC that day. The same forecast cycle from the NAM showed an elevated warm layer present with a depth of approximately $1500 \mathrm{~m} \mathrm{(4921} \mathrm{ft)} \mathrm{and} \mathrm{a} \mathrm{maximum}$ temperature of $2.8^{\circ} \mathrm{C}\left(37^{\circ} \mathrm{F}\right)$ valid at $1200 \mathrm{UTC}$. This layer was not saturated, so introducing precipitation would result in evaporational cooling, and therefore the wet-bulb temperature would be a more accurate representation of this layer after saturation. In this case the wet-bulb temperature was $\sim 1.2^{\circ} \mathrm{C}\left(34.2^{\circ} \mathrm{F}\right)$, which is not as sufficient to fully melt precipitation falling through that layer. Both the 4-km NAM and Weather Research and Forecasting Nonhydrostatic Mesoscale Model (WRF-NMM) depicted a very similar elevated warm layer but did not have a sub-freezing surface layer. The 0000 UTC GFS, High Resolution Rapid 


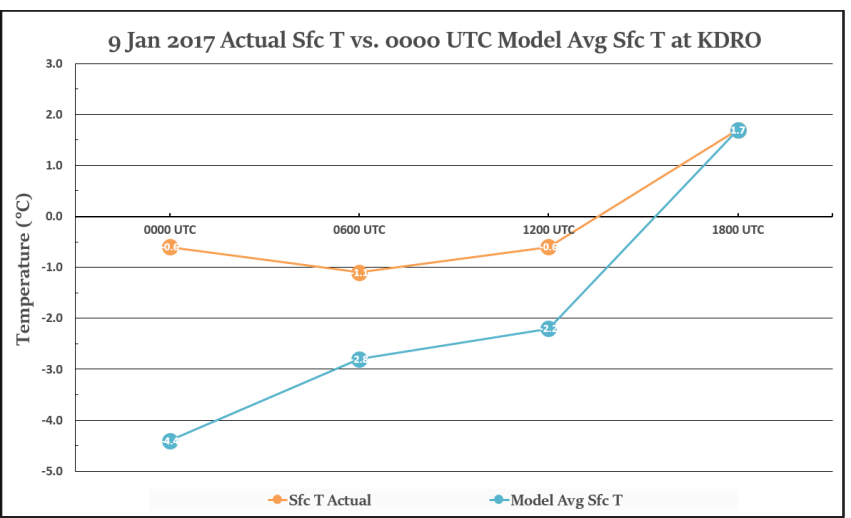

Figure 14. Same as Fig. 12 except for KDRO.

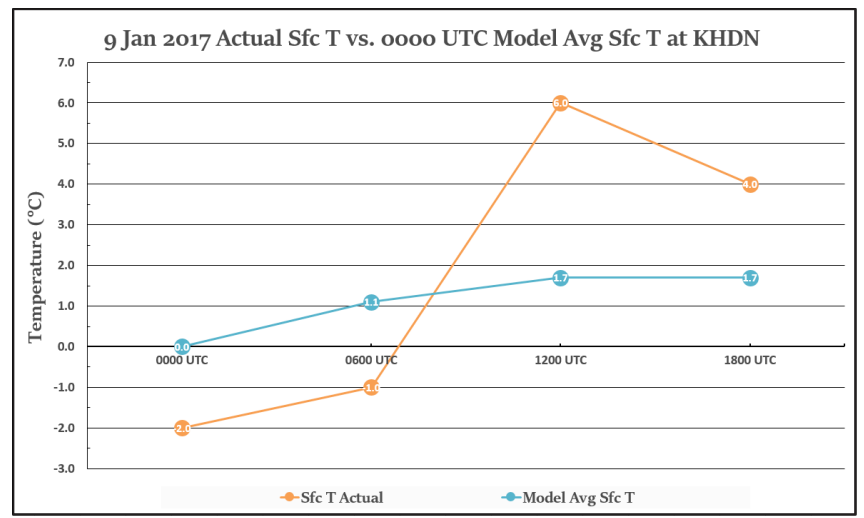

Figure 15. Same as Fig. 12 except for KHDN.

Refresh (HRRR), and WRF-Advanced Research WRF (WRF-ARW) forecast soundings valid at 1200 UTC also did not have a sub-freezing surface layer present throughout the duration of the event, which was entirely inaccurate. These model errors made it extremely difficult to determine the precipitation type even hours leading up to the icing. Forecast soundings for other locations where freezing rain occurred (Steamboat Springs Airport and KDRO) were subject to the same errors as mentioned for KGJT.

Almost a week in advance, extended forecast models as well as the CW3E were projecting a strong AR event to occur during the 8-10 January timeframe. Guidance indicated PWAT values would be two to three standard deviations above normal for early January (Bunkers 2006) as the various embedded disturbances trekked across the western slope of Colorado. As a result, the primary forecast concern was the potential for heavy snow in the mountains, particularly any southwest-facing slopes that would be most favored in this flow regime. Situational awareness leading up to the freezing-rain event that occurred on 9 January remained focused on the increasing snowfall projections and impacts across
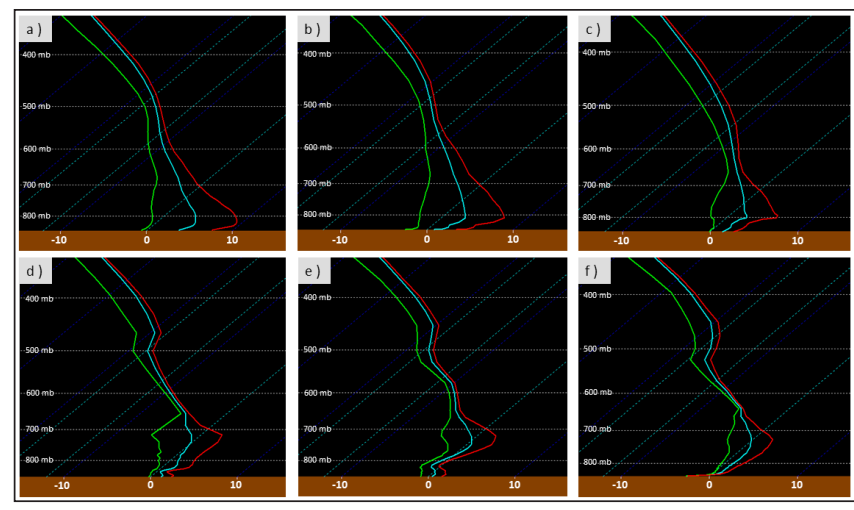

Figure 16. BUFKIT sounding for KGJT 0000 UTC 9 January 2017 run cycle valid at 1200 UTC: a) GFS; b) HRRR; c) WRF-ARW; d) WRF-NMM; e) 4-km NAM; f) 12-km NAM, [temperature (red, ${ }^{\circ} \mathrm{C}$ ), wet-bulb temperature (blue, ${ }^{\circ} \mathrm{C}$ ), dewpoint (green, ${ }^{\circ} \mathrm{C}$ )].

the region, such as hazardous travel and the closure of the Crested Butte Ski Area. Even so, forecasters at WFO GJT knew that the abundance of warm air aloft associated with the extreme AR would be a forecast challenge in the short term. The general consensus was that the mixing associated with the influx of warm air would occur quickly enough to allow precipitation to transition from snow to a wintry mix to rain without much impact. Finally, the significant clearing late on 8 January that reinforced the cold planetary boundary layer was not projected in the models, which drastically altered the forecast temperatures and precipitation type.

\section{Societal impact and forecast messaging}

As a result of the extremely rare ice storm and the fact that freezing rain was not in the initial forecast issued by WFO GJT, travel was severely impacted across portions of western Colorado and eastern Utah. Several roads and highways were shut down owing to numerous accidents and vehicles sliding off roadways. Ice accrual occurred on major roads such as Interstate 70 (I-70) and Colorado highways 160 and 141. More than 70 vehicle accidents were reported to the Grand Junction Police Department (GJPD) on 9 January, and likely many more were not reported. One GJPD officer had to walk two miles from Horizon Drive in Grand Junction, near KGJT, to a location on I-70 where a multivehicle accident had occurred. The use of magnesium chloride on the roads by the Colorado Department of Transportation (CDOT) was minimally effective as it was diluted by the freezing rain while also adding more liquid that eventually froze because 
of the cold temperatures. Hospitals and dispatch centers were overwhelmed by the sudden and unexpected increase of requests for services. A record number of people - more than 200 - were admitted to hospital emergency rooms as a result of fall-related injuries. Most of the injuries involved broken hips and other extremity injuries, such as broken arms and fingers. Local schools across Mesa County were forced to delay and eventually cancel classes because of the extremely hazardous travel conditions. To exacerbate the situation, the ice storm occurred on the first school day after the winter break with freezing rain falling just hours before classes started. Power outages also occurred in the towns of Palisade and Clark, Colorado. Finally, traffic was impacted at KGJT. The runways were closed for 3 $\mathrm{h}$ after a Gulfstream plane landed and needed the entire runway to brake. Airport employees were also unable to make it to work because of the poor road conditions. Apart from a closure on Christmas Day in 2015 due to heavy snow accumulations, this was the first time in $43 \mathrm{y}$ that KGJT had to close, as noted by the Chief of Airside Operations who had worked at KGJT since 1974. Together, these major impacts to Mesa County led to the establishment of an Emergency Operations Center (EOC) in Grand Junction at 1330 UTC.

Between 1330 and 1500 UTC on 9 January, social media was flooded with reports of freezing rain as well as numerous accidents and spin-outs. This was particularly true in both Mesa and La Plata counties and along I-70, which is a major travel route in the region. As a result of the widespread and extreme impacts, the decision was made to upgrade the ongoing Freezing Rain Advisories to Ice Storm Warnings. This led to enhanced messaging and the trigger of the Emergency Alert System (EAS). After receiving the EAS, numerous briefings were requested by the Grand Junction EOC, several dispatch centers, both the northwestern and southwestern Colorado Regional Field Managers, and CDOT. Additionally, this caused the Ice Storm Warning to become prominent on the Watch, Warning, and Advisory map on the WFO GJT website as opposed to having the Freezing Rain Advisory be hidden by the ongoing Winter Storm Warnings. This action increased the visibility of the Ice Storm Warnings and highlighted the rare, extreme impacts. The update made to the Area Forecast Discussion at 1600 UTC stressed "We can not emphasize enough how dangerous travel conditions are on roadways at the moment. If you do not have to be out on the roadways, please stay home!"

\section{Conclusion}

The 9 January 2017 ice storm was a rare event for the western slope of Colorado. This statement is supported by the lack of any ice storm of this magnitude being documented at Grand Junction since climate records began in 1893, as well as based on anecdotal experiences from long-time residents and core partners. This event brought major impacts to Mesa, Delta, Garfield, and La Plata counties as well as minor impacts to Montrose, Gunnison, and Routt counties. Minor impacts also were reported in Grand County, Utah. A graphical depiction of the ice storm's impact by county can be found in Fig. 17. The ongoing extreme AR event produced heavy snow over the mountains, particularly on southwestfacing slopes. The excessive mountain snow became the primary forecast issue during the 8-10 January time period, although WFO GJT forecasters were concerned with the depth of the warm Pacific air aloft associated with the extreme AR and how it would impact ongoing valley inversions. The resulting elevated warm layer did become sufficient for completely melting the frozen hydrometeors the morning of 9 January with a depth of $1000 \mathrm{~m}(3281 \mathrm{ft})$ and a maximum temperature of $5^{\circ} \mathrm{C}$ $\left(41^{\circ} \mathrm{F}\right)$. The other challenge for WFO GJT forecasters was the rapidly clearing skies on the night of 8 January that, when combined with recent snowfall, strengthened valley cold pools and resulted in conditions favorable for freezing precipitation the next day. This subfreezing surface layer was shallow with a depth of only $500 \mathrm{~m}(1640 \mathrm{ft})$ but allowed the hydrometeors to freeze on contact. Although model guidance indicated that the aforementioned inversions would mix out, the

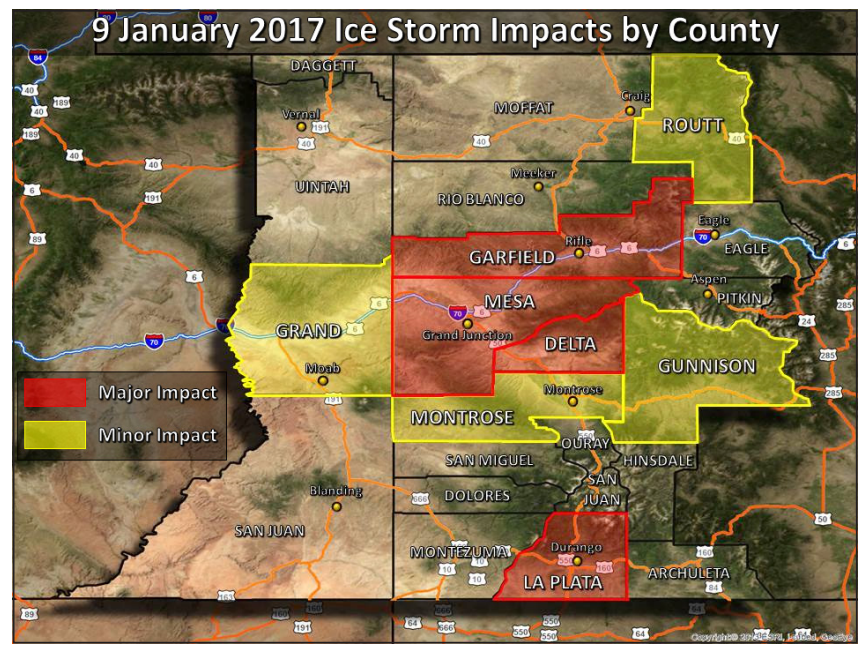

Figure 17. Graphical depiction of major and minor impacts by county from the 9 January 2017 ice storm. 
projected timing was too early, possibly because of the strengthening of the cold pools resulting from the clear skies overnight. Consequently, temperature inversions in the Grand Valley remained in place until the midafternoon hours on 9 January, which resulted in a prolonged freezing-rain event.

Numerous lessons were learned as a result of the 9 January ice storm. Internal suggestions include altering staffing on the overnight shift when a challenging forecast is ongoing to increase situational awareness. In the future, having a focus on what is occurring upstream will better prepare forecasters for any freezing precipitation potential. As far as improving communications with core partners, plans were made to build trust continually within relationships by remaining transparent and utilizing communication tools such as NWSChat, Situation Reports, and conference calls during both active and quiet weather. Finally, the rarity of this event, compounded with the magnitude of impacts to the public and weather partners, resulted in a change to local highlight criteria. WFO GJT will now only issue Ice Storm Warnings rather than Freezing Rain Advisories for all subsequent freezing precipitation events. This will result in improved messaging as well as activation of the EAS on NOAA Weather Radios and other alert systems.

Acknowledgments. The authors thank Julie Malingowski for her upper-air temperature profile analysis showing the evolution of temperatures below $500 \mathrm{hPa}$ with observed soundings, as well as the late Larry Smith for his work on the Grand Junction Ice Storm Assessment from which some information was included in this paper. Additionally, we would like to thank the WFO GJT staff who participated in an anonymous survey and provided input on forecast operations post-ice storm. Finally, we are grateful to NWS Central Region who, after reading our assessment, accepted our petition to stop issuing Freezing Rain Advisories in favor of Ice Storm Warnings for all future freezing precipitation events.

\section{REFERENCES}

Bernstein, B. C., 2000: Regional and local influences on freezing drizzle, freezing rain, and ice pellet events. Wea. Forecasting, 15, 485-508, CrossRef.

, and B. Brown, 1997: A climatology of supercooled large drop conditions based upon surface observations and pilot reports of icing. Preprints, Seventh Conf. on Aviation, Range, and Aerospace Meteorology, Long Beach, CA, Amer. Meteor. Soc., 82- 87, CrossRef.

Bunkers, M., 2006: Precipitable water plots: U. S. radiosonde locations for PW climatology. [Available online at www. spc.noaa.gov/exper/soundingclimo/.]

Changnon, S. A., and T. R. Karl, 2003: Temporal and spatial variations of freezing rain in the contiguous United States: 1948-2000. J. Appl. Meteor., 42, 1302-1315, CrossRef.

Cortinas, J. V., Jr., B. C. Bernstein, C. C. Robbins, and J. W. Strapp, 2004: An analysis of freezing rain, freezing drizzle, and ice pellets across the United States and Canada: 1976-90. Wea. Forecasting, 19, 377-390, CrossRef.

Garvert, M., B. Smull, and C. Mass, 2007: Multiscale mountain waves influencing a major orographic precipitation event. J. Atmos. Sci., 64, 711-737, CrossRef.

Glickman, T. S., Ed., 2000: Glossary of Meteorology. 2d ed. American Meteorological Society, 855 pp.

Kocin, P. J., 1997: Some thoughts on the societal and economic impacts of winter storms. Proc. Workshop on Social and Economic Impacts of Weather, Boulder, CO, NCAR, 55-60. [Available online at sciencepolicy.colorado.edu/ socasp/weather1/kocin.html.]

Meyers, M. P., D. Phillips, M. D. Aleksa, and J. D Colton, 2015: The mesoscale implications for a freezing rain event for the 2014 opening day at Steamboat Ski Resort. Presented at the 16th Conference on Mesoscale Processes, Boston, MA, Amer. Meteor. Soc. [Available online at ams.confex.com/ams/16Meso/webprogram/ Paper274561.html.]

Ralph, F. M., J. J. Rutz, J. M. Cordeira, M. Dettinger, M. Anderson, D. Reynolds, L. J. Schick, and C. Smallcomb, 2019: A scale to characterize the strengths and impacts of atmospheric rivers. Bull. Amer. Meteor. Soc., 100, 269-289, CrossRef.

Rauber, R. M., L. S. Olthoff, M. K. Ramamurthy, and K. E. Kunkel, 2000: The relative importance of warm rain and melting processes in freezing precipitation events. $J$. Appl. Meteor., 39, 1185-1195, CrossRef.

, D. Miller, and K. E. Kunkel, 2001: A synoptic weather pattern and sounding-based climatology of freezing precipitation in the United States east of the Rocky Mountains. J. Appl. Meteor., 40, 1724-1747, CrossRef. 
Reeves, H. D., and D. J. Stensrud, 2009: Synoptic-scale flow and valley cold pool evolution in the western United States. Wea. Forecasting, 24, 1625-1643, CrossRef.

Robbins, C. C, and J. V. Cortinas Jr., 1996: A climatology of freezing rain in the contiguous United States: preliminary results. Preprints. 15th Conf. on Weather Analysis and Forecasting, Norfolk, VA, Amer. Meteor. Soc., 124-126. , and J. V. Cortinas Jr., 2002: Local and synoptic environments associated with freezing rain in the contiguous United States. Wea. Forecasting, 17, 47-65, CrossRef.

Rutz, J. J., W. J. Steenburgh, and F. M. Ralph, 2015: The inland penetration of atmospheric rivers over western North America: A Lagrangian analysis. Mon. Wea. Rev., 143, 1924-1944, CrossRef.

Stewart, R. E., and P. King, 1987: Freezing precipitation in winter storms. Mon. Wea. Rev., 115, 1270-1280, CrossRef. , and R. W. Crawford, 1995: Some characteristics of the precipitation formed within winter storms over eastern Newfoundland. Atmos. Res., 36, 17-37, CrossRef.

, J. D. Marwitz, J. C. Pace, and R. E. Carbone, 1984: Characteristics through the melting layer of stratiform clouds. J. Atmos. Sci., 41, 3227-3237, CrossRef.

Zerr, R. J., 1997: Freezing rain: An operational and theoretical study. J. Appl. Meteor., 36, 1647-1661, CrossRef. 